\title{
DESINTEGRAÇÃO ECONÔMICA E FRAGMENTAÇÃO DA GOVERNANÇA REGIONAL NA AMÉRICA DO SUL EM TEMPOS DE COVID-19
}

\author{
Pedro Silva Barros' \\ Julia de Souza Borba Gonçalves² \\ Sofía Escobar Samurio ${ }^{3}$
}

\begin{abstract}
SINOPSE
0 objetivo deste artigo é analisar os efeitos da pandemia da Covid-19 sobre o comércio e a governança da América do Sul. A hipótese é que a crise gerada pela Covid-19 acentuou as tendências anteriores de desintegração econômica e fragmentação política. Analisa-se como organizações regionais da África, América Central, América do Sul e Europa responderam à Covid-19. No caso da América do Sul, avalia-se o papel do Foro para o Progresso e Desenvolvimento da América do Sul (Prosul) para oferecer respostas à crise, considerando as iniciativas desde o surgimento da crise, sua agenda para Saúde, as interações entre os governos e seu arcabouço institucional. Avalia-se a dinâmica comercial intrarregional, com ênfase nas exportaçõ̃es e importações do Brasil com os países vizinhos. Conclui-se que há uma espiral entre desintegração comercial e fragmentação da governança, que se retroalimenta e tende a prolongar a crise na América do Sul mais que em outras regiões do mundo.

Palavras-chave: desintegração econômica; governança regional; América do Sul; Covid-19.
\end{abstract}

\begin{abstract}
The aim of this article is to analyze the effects of the Covid-19 pandemic on trade and governance in South America. The hypothesis is that the crisis generated by the Covid-19 has exacerbated previous trends of economic disintegration and political fragmentation. We analyze how regional organizations in Africa, Central America, South America and Europe responded to the Covid-19 pandemic. In the case of South America, we analyzed the role of the Forum for the Progress of South America (Prosur) to provide responses to the crisis, considering the initiatives that were implemented since the emergence of the Covid-19, its agenda for Health, the interactions between governments and its institutional framework. We also analyzed the intra-regional trade dynamics, with emphasis on exports and imports from Brazil with its neighboring countries. We conclude that there is a spiral between commercial disintegration and fragmentation of governance, which feeds back and tends to extend the crisis in South America more than in other regions of the world.
\end{abstract}

Keywords: economic disintegration; regional governance; South America; Covid-19.

JEL: F02.

Artigo recebido em 31/7/2020 e aprovado em 31/8/2020.

DOl: http://dx.doi.org/10.38116/bepi27art8

\section{INTRODUÇÃO}

Durante a última década, a América do Sul tem se desintegrado econômica e comercialmente e se fragmentado politicamente. Esse movimento, que já havia sido muito forte em 2019, foi intensificado no primeiro semestre de 2020, período em que o debate internacional orbitou em torno da Covid-19.

1. Técnico de planejamento e pesquisa na Diretoria de Estudos e Relações Econômicas e Políticas Internacionais (Dinte) do Ipea.

2. Pesquisadora do Programa de Pesquisa para o Desenvolvimento Nacional (PNPD) na Dinte/lpea.

3. Pesquisadora do PNPD na Dinte/lpea; e doutoranda em economia na Universidade de Brasília (UnB). 
Os primeiros casos e desdobramentos da doença foram observados entre o final de dezembro de 2019 e o início de fevereiro de 2020 na China e em alguns países da Europa (com destaque para Itália e Espanha), logo se espalhando por toda a região. Em março, a Organizaçáo Mundial da Saúde (OMS) declarou pandemia. Seus efeitos são percebidos em várias perspectivas, entre elas o comércio, a governança regional e a cooperaçáo internacional. No decorrer do primeiro semestre de 2020, a América do Sul tornou-se uma das regiôes mais afetadas do mundo, tanto em relação ao número de casos e de mortes quanto em relação à queda do comércio intrarregional. Observam-se na região sul-americana decisóes unilaterais e falta de articulação e posiçôes comuns em fóruns políticos, ao mesmo tempo que se interrompe o livre movimento em zonas fronteiriças.

O objetivo deste artigo é analisar os efeitos da pandemia para o comércio intrarregional e para a governança regional, principalmente sobre saúde. Parte-se de duas hipóteses fundamentais: a primeira, de que a baixa eficiência da governança regional na América do Sul, que se contrasta com outras regiôes do mundo, ampliou os impactos da crise e, potencialmente, cria barreiras para a retomada econômica pós-Covid-19; a segunda, de que a crise gerada pela Covid-19 acentuou as tendências anteriores de desintegração econômica e fragmentação política.

O artigo está organizado em três partes, além desta introdução e das conclusóes. Na segunda seção, são analisadas as organizaçóes regionais (na África, América Central, América do Sul e Europa) e suas respostas aos efeitos da pandemia da Covid-19. Na terceira seção, busca-se sistematizar a atuação do Foro para o Progresso e Desenvolvimento da América do Sul (Prosul) e avaliar como as transformaçóes políticas na América do Sul vêm impactando a governança regional em saúde. Na quarta seção, apresenta-se e avalia-se a dinâmica comercial intrarregional na América do Sul, com ênfase nas exportaçóes e importaçóes do Brasil com os países vizinhos. Compara-se o comportamento recente do comércio Brasil-Argentina vis-à-vis Alemanha-França, Estados Unidos-México e China-Japão como forma de avaliar a queda do principal comércio bilateral da América do Sul em relação a situaçôes análogas em outras regiôes. Para avaliar um possível impacto da crise de governança regional sobre o comércio exterior brasileiro durante a pandemia, analisou-se o comércio do Brasil com os países vizinhos no primeiro e segundo trimestres de 2020 em comparaçáo com iguais períodos de 2018 e 2019, quando o comércio regional do Brasil já estava em queda. A divisão em trimestres justifica-se porque, no caso brasileiro, os efeitos comerciais da pandemia se iniciaram somente no final de março: no acumulado de janeiro a março (primeiro trimestre), houve pouco impacto da pandemia no comércio exterior - apenas no acumulado de abril a junho (segundo trimestre) é que se concentraram os efeitos negativos da pandemia no comércio exterior do Brasil.

\section{ORGANIZAÇÕES REGIONAIS DIANTE DA COVID-19}

O sistema internacional foi organizado para evitar guerras e superar crises. Tanto as organizaçóes mundiais como as regionais concentram suas atividades e têm sua legitimidade respaldada nos momentos de instabilidade. Esta seção busca apresentar, de forma comparada, a atuação de organizaçôes regionais selecionadas em relaçáo à saúde pública e a temas econômicos durante o primeiro semestre de 2020.

Em abril, a OMS declarou que a América do Sul era o novo epicentro da Covid-19. Em maio, a OMS publicou a atualização do informe Operational Planning Guidelines to Support Country Preparedness and Response (WHO, 2020), a fim de oferecer um guia prático para dar suporte às autoridades nacionais para darem respostas à Covid-19. Entre as açôes (steps) que deveriam ser tomadas e que abrangem o nível regional e global, destacam-se as seguintes. 
Consultar os países vizinhos, outros países e órgãos regionais sobre o planejamento e a gestão da pandemia da Covid-19 em todos os setores. (...) Garantir que produtos WASH (water, sanitation and hygiene) críticos sejam priorizados nas iniciativas globais e regionais de apoio à cadeia de fornecimento; apoiar a produção local de itens críticos de higiene e prevençáo (WHO, 2020, p. 5 e 12, tradução nossa).

Ao analisar como as organizaçóes regionais têm respondido à pandemia da Covid-19, parte-se do pressuposto de que muitas têm a competência de dar respostas a desafios comuns, pois são capazes de promover a cooperação entre Estados que participam de tal organização por meio dos mecanismos e regras que foram estabelecidos. Assume-se, então, desde a perspectiva neoinstitucionalista, que as instituiçôes importam, pois oferecem informaçóes, reduzem custos de transação, dão mais credibilidade aos compromissos e podem ter sua utilidade maximizada se os Estados as utilizam para coordenar suas açôes visando à cooperação (Keohane e Martin, 1995).

Nesse sentido, o quadro 1 sistematiza as informaçóes, de janeiro a junho de 2020, sobre como as organizaçôes regionais, o Prosul, o Sistema de Integração Centro-Americano (Sica), a Uniáo Africana e a União Europeia têm agido para propor medidas conjuntas.

\section{QUADRO 1}

Respostas de organizações regionais à pandemia da Covid-19

\begin{tabular}{|c|c|c|c|c|}
\hline Blocos regionais & União Africana & União Europeia & Prosul & Sica \\
\hline Quantas reuniões foram promovidas entre autoridades máximas dos países? & Nenhuma & Seis & Três & Uma \\
\hline Todos os países participaram das reuniões? & - & Sim & Não & Não \\
\hline Elaboraram um plano de ação conjunto? & Sim & Sim & Não & Sim \\
\hline Adotaram ações sobre comércio intrarregional e recuperação econômica? & Sim & Sim & Não & Sim \\
\hline Receberam doações extrarregionais?'1 & Sim & Não & Não & Sim \\
\hline
\end{tabular}

Fonte: União Africana, União Europeia, Prosul e Sica.

Elaboração dos autores.

Nota: ${ }^{1}$ Outro aspecto que vem se destacando no enfrentamento à Covid-19 são as doações (em dinheiro ou materiais para a prevenção da doença) aos países africanos e latino-americanos. A União Africana recebeu a doação de € 10 milhões da União Europeia e de US\$ 1 milhão do Japão para a implementação da Africa Joint Continental Strategy for Covid-19 Outbreak; e, da parceria com a MasterCard Foundation, 1 milhão de kits de teste e o posicionamento de 10 mil agentes comunitários de saúde no continente (Africa Union, 2020f; 2020g; 2020h). No caso do Sica, destacam-se as doações de 30 mil testes de Covid-19 da Rússia, 182 mil kits de testagem da Coreia do Sul (Sica, 2020c; 2020d). Criou-se um fundo de emergência de US\$ 4 milhões para Honduras, Belize, Guatemala e Nicarágua, com o apoio da China (Taiwan) (Sica, 2020e). No caso da América do Sul, as doações da China apenas se direcionaram aos países, não ao Prosul.

O Prosul, em comparação com os demais, não tem sido efetivo para coordenar ações conjuntas entre os países-membros e os demais países da região que não participam do Prosul. No que diz respeito às três primeiras questôes do quadro 1 , o Prosul realizou três reunióes presidenciais e emitiu duas declaraçôes presidenciais; as reuniōes, contudo, não contaram com todos os países da região. O presidente brasileiro, que havia estado no Chile em março de 2019 para assinar a primeira declaraçáo que deu origem ao Prosul, não participou das reuniōes via videoconferência.

A União Europeia, a princípio, não respondeu de maneira conjunta ao surgimento da Covid-19 na Europa, até que, em maio de 2020, lançou a Coronavirus Global Response Initiative com parceiros 
globais. ${ }^{4,5}$ O Conselho Europeu ${ }^{6}$ reuniu-se seis vezes e aprovou o roteiro para a recuperação, o orçamento de longo prazo (2021-2027) e o plano de recuperação de $€ 1,8$ trilhão. Ademais, a União Europeia conta com o European Centre for Disease Prevention and Control (ECDC), criado para fortalecer a capacidade de resposta diante de doenças infecciosas e disponibilizar informaçóes sobre o número de contagiados, recuperados e mortos em cada país, além de informes, protocolos e artigos científicos sobre a Covid-19 e outras doenças. Além do ECDC, o tema tem sido abarcado por todas as instâncias da organização (União Europeia, 2020a; 2020b; 2020c).

A Uniáo Africana e centro africano de controle e prevenção de doenças (Africa Centres for Disease Control and Prevention - Africa CDC) lançaram o Africa Covid-19 Response Fund em parceria com a iniciativa Afro Champions. A operação do fundo é supervisionada pela União Africana, pelo Africa CDC, em que o conselho consultivo composto por representantes dos setores públicos e privados e um painel de especialistas supervisionam a gestão do fundo. $\mathrm{O}$ fundo visa atuar em três frentes: i) aquisição de suprimentos médicos e mercadorias; ii) envio de socorristas em todo o continente; e iii) apoio socioeconômico à população mais vulnerável (Garcia, Assis e Ribeiro, 2020). A institucionalidade consolidada da organização possibilitou que ela desse respostas à pandemia prontamente, pois foram realizadas discussóes prévias sobre como lidar com o vírus antes que chegasse ao continente e se preparar para os impactos econômicos e sociais. ${ }^{7}$ Tanto o Africa CDC, como órgáo especializado na temática de saúde, como os demais órgáos e instâncias estáo debatendo e propondo medidas acerca dos impactos da Covid-19 sobre o continente (Africa Union, 2020a; 2020b; 2020c; 2020d; 2020e).

O Sica publicou a declaraçáo dos chefes de Estado sobre a necessidade de atuar conjuntamente diante da Covid-19 e elaborou o Plan de Contingencia Regional del Sica frente al Covid-19, em que se incluem a criação do Observatório Regional Sica-Covid-19, com informaçóes sobre as açôes que os países têm adotado, e a sistematizaçáo de informaçáo sobre casos de Covid-19 (Sica, 2020a; 2020b). Nota-se que as três instituiçóes que conseguiram dar respostas em relação aos temas de saúde pública, quanto aos temas econômicos, possuem em comum o fato de terem institucionalidade (tratado constitutivo, ratificado pelos parlamentos nacionais), burocracia própria e orçamento anual predefinido. O Prosul, por sua vez, não tem nenhuma dessas características.

\section{GOVERNANÇA REGIONAL SUL-AMERICANA: DA UNIÃO DE NAÇÕES SUL-AMERICANAS (UNASUL) AO PROSUL}

Governança diz respeito aos modos de coordenaçáo institucionalizados, por meio dos quais decisóes coletivas são adotadas e implementadas (Börzel, 2016). Para que seja eficiente, a governança regional requer uma base institucional para que as normas e regras estabelecidas possam prevalecer (Nolte,

\footnotetext{
4. A conferência de doadores foi convocada pela União Europeia e por países como Canadá, França, Alemanha, Itália (que assegurará a futura presidência do Grupo dos Vinte - G20), Japão, Reino da Arábia Saudita (atualmente responsável pela presidência do G20), Noruega, Espanha e Reino Unido. Disponível em: <https://ec.europa.eu/commission/presscorner/detail/pt/ip_20_797>. Acesso em: 17 ago. 2020.

5. Disponível em: <http://www.tepsa.eu/the-eus-global-response-to-the-covid-19-crisis-with-a-focus-on-the-eastern-neighbourhood-andafrica-philipp-brugner-and-klaus-schuch-ogfe-austria/>.

6. Os membros do Conselho Europeu são os chefes de Estado ou de governo dos 27 Estados-membros da União Europeia, o presidente do Conselho Europeu e o presidente da Comissão Europeia. Disponível em: <https://www.consilium.europa.eu/pt/european-council/>. Acesso em: 17 ago. 2020.

7. Disponível em: <https://www.youtube.com/watch?v=glurD2HOhOk>.
} 
2019). Na América Latina, o regionalismo tem sido uma ferramenta de governança para o amparo e o reforço da soberania dos Estados (Riggirozzi, 2020).

Ao discutir a governança regional na América do Sul, cabe destacar o papel da Unasul como o espaço regional sul-americano para tratar dos temas relativos à integração regional em toda a América do Sul e que vão além de seu aspecto comercial. O surgimento da Unasul é analisado, principalmente, pelo conceito "regionalismo pós-hegemônico", cujas características são a volta do conteúdo político e as estratégias de desenvolvimento para se pensar a regiáo sul-americana (Riggirozzi e Tussie, 2012).

A Unasul foi capaz de agrupar todos os países do subcontinente e promover decisões por consenso, mesmo com governos seguindo diferentes orientaçóes políticas, além de criar doze conselhos setoriais e um quadro institucional capaz de fortalecer a propagação de políticas públicas regionais. A Unasul foi eficiente na construção de uma confiança regional, pela atuação nas missóes eleitorais, do Conselho Eleitoral, ou em momentos de crises e instabilidades - por exemplo, na Bolívia, na Colômbia, no Equador, no Paraguai e na Venezuela (Fuccille et al., 2017).

A atual fragmentação política da região é decorrente, em parte, das mudanças internas nos países, marcadas pela crescente polarização política, que acaba incidindo nos temas de política exterior. A eleição de Mauricio Macri (Argentina), em 2015, o impeachment de Dilma Rousseff (Brasil), em 2016, a eleição de Sebastián Piñera (Chile), em 2017, e a eleição de Ivan Duque (Colômbia), em 2018, podem ser considerados os fatores que levaram esses países, que anteriormente participaram ativamente da Unasul, a adotar o discurso de que a organização seguia a "ideologia bolivariana" e sua estrutura institucional tinha um custo elevado sem apresentar resultados efetivos.

A desintegração da Unasul se acentuou em 2017, quando náo houve um consenso entre os países sobre o sucessor de Ernesto Samper na Secretaria-Geral. Em agosto do mesmo ano, foi criado o Grupo de Lima para propor uma soluçáo à crise na Venezuela, em vez de se discutir o tema no âmbito da Unasul. Agravaram-se as críticas dos países em relação aos propósitos e à eficiência da Unasul, até que, em abril de 2018, quando a presidência pro tempore passou da Argentina para a Bolívia, seis países (Argentina, Brasil, Chile, Colômbia, Paraguai e Peru) anunciaram a suspensão de participação na organização (Narea e Benzi, 2020).

As reuniōes de ministros do Conselho Sul-Americano de Infraestrutura e Planejamento (Cosiplan) foram interrompidas a partir de dezembro de 2017. A última reunião do Instituto Sul-Americano de Governo da Saúde (Isags) ocorreu em 2019, com participação reduzida. Não há registros de continuidade das atividades do Conselho de Defesa Sul-Americano (CDS) e de órgáos relacionados nos últimos anos. Do ponto de vista da fragmentaçáo política, a ausência de uma instância efetiva para promover a governança regional foi marcada principalmente pelo enfraquecimento e pela extinção, na prática, da Unasul.

No começo de 2019, o Grupo de Lima passou a reconhecer Juan Guaidó como o presidente legítimo da Venezuela e, consequentemente, abandonou o objetivo inicial do agrupamento: promover o diálogo entre o governo e a oposição (Barros e Gonçalves, 2019). Em março de 2019, os presidentes colombiano e chileno propuseram a criaçáo do Prosul para a cooperaçáo e a integraçáo da América do Sul em substituiçáo à Unasul, com o objetivo declarado de manter o acervo da integraçáo regional operando sob uma institucionalidade muito reduzida e flexível. Participam Argentina, Brasil, Chile, Colômbia, Equador, Guiana, Paraguai e Peru. ${ }^{8}$ Os então mandatários buscaram legitimar o novo 
formato com o discurso de que o Prosul é uma integração regional que não está baseada em ideologias, em contraste com a Unasul, que, segundo esse mesmo discurso, estava com excesso de ideologia e burocracia - esse é um discurso presente nas falas dos presidentes do Chile e da Colômbia, ${ }^{10}$ países que deram impulso e ocuparam as duas primeiras presidências pro tempore do Prosul.

Na primeira declaração de presidentes, foram indicadas as áreas prioritárias de infraestrutura, energia, saúde, defesa, segurança e combate ao crime, prevenção e gerenciamento de desastres naturais para a ação conjunta dos países. ${ }^{11} \mathrm{O}$ objetivo do Prosul, conforme o documento com suas diretrizes de funcionamento, é "fortalecer e priorizar o diálogo entre os países participantes para construir de maneira participativa um espaço de coordenação e cooperação que nos permita avançar progressivamente a uma maior integração e ação coordenada na América do Sul” (tradução nossa). ${ }^{12}$

Atualmente, a pandemia da Covid-19 e seus efeitos têm-se colocado como entraves para promover a cooperação entre os países da América do Sul, assim como a ausência de liderança regional, decorrente de problemas domésticos dos vizinhos regionais e da ausência de maior protagonismo brasileiro. Das reunióes em que náo participam todos os representantes sul-americanos ao fechamento das fronteiras e às declaraçôes presidenciais sobre a situação, há uma dificuldade generalizada para coordenar esforços para a mitigação da propagação do vírus e vislumbrar outros temas de cooperaçáa regional. Em contraste com outras regiôes, não há indícios de concertação para uma agenda de retomada econômica pós-Covid-19.

\subsection{A governança regional sul-americana em saúde}

A crise provocada pela pandemia da Covid-19 encontrou na América do Sul um espaço regional sem instituiçóes executivas e técnicas funcionando adequadamente. Ainda que o Prosul declarasse que manteria o acervo da integração, notoriamente não foi o caso da saúde: tanto o Conselho de Saúde Sul-Americano como o Isags não estavam ativos e não haviam sido substituídos ou incorporados ao Prosul.

No que diz respeito à institucionalidade,

institucionalmente, a Unasul criou um Conselho de Saúde que trabalha em nível ministerial para consolidar a integração sul-americana no campo da saúde por meio de políticas e uma agenda proposta pelos membros juntamente com grupos técnicos temáticos e redes temáticas. (...) A Unasul se engajou em um novo tipo de diplomacia em uma dupla estratégia: i) a diplomacia intrarregional, centrada na cooperação intrarregional; e ii) a diplomacia transversal ou extrarregional, buscando redefinir a divisão norte/sul nas negociaçóes e estratégias de saúde (Riggirozzi, 2015, p. 420-421, traduçáo nossa).

Em relação às políticas sanitárias, Riggirozzi (2020) aponta sete exemplos de açôes exitosas por parte dos países e das instituiçóes regionais na América do Sul: i) a assinatura da Carta de Buenos

9. "Faz mais de cinco anos que os presidentes da América do Sul não se reúnem. A Unasul falhou devido ao excesso de ideologismo e burocracia" (tradução nossa). Disponível em: <https://www.cnnchile.com/pais/sebastian-pinera-prosur-ideologia-burocracia-unasur_20190316/>. Acesso em: 16 ago. 2020.

10. "Ao dar esse passo hoje, estamos recuperando o sentido de uma integração conceitual mais do que baseada em ideologias, mas sim em princípios na defesa da democracia, em defesa dos direitos humanos e, claramente, em economias de mercado com grande sentido de responsabilidade social" (tradução nossa). Disponível em: <https://www.eltiempo.com/politica/gobierno/duque-dice-que-prosur-marca-unhito-en-lo-que-debe-ser-el-proceso-de-integracion-340882>. Acesso em: 16 ago. 2020.

11. Disponível em: <https://tinyurl.com/yy5nrhxv>.

12. Disponível em: <https://foroprosur.org/wp-content/uploads/2020/09/Declaracion-de-Ministros-de-RREE-1.pdf>. 
Aires sobre Compromisso Social, de 2000, que estabelece um quadro de obrigaçóes para alcançar o acesso a serviços integrais em saúde; ii) o Plano Estratégico de Ação Social do Mercosul, ${ }^{13}$ em 2010, sobre a harmonização de políticas específicas de saúde pública; iii) o sistema Registro Mercosul de Doação e Transplante (Registro Mercosur de Donación y Trasplante - Donasur), registro de doaçóes de órgãos; iv) marcos normativos para regular o controle epidemiológico e respostas à propagação de dengue, zika e chikungunya; $v$ ) os presidentes do Mercosul trabalharam em conjunto na OMS para a flexibilização das patentes dos medicamentos e para que houvesse mais opçôes para desenvolver uma vacina contra a $\mathrm{H} 1 \mathrm{~N} 1$; vi) a açáo coordenada entre Mercosul e Unasul para a compra conjunta de medicamentos na Organização Pan-Americana de Saúde (Opas); e vii) a criação, na Unasul, do banco de preços compartilhado nas negociaçôes sobre produtos farmacêuticos.

O Isags capitalizou sobre o papel internacional do Brasil, que na época exerceu um grande protagonismo global no questionamento de normas sobre o acesso a medicamentos e o direito à saúde em várias agências da Organização das Naçóes Unidas (ONU) e por meio da Cooperação Sul-Sul. O Isags apoiou reformas para a universalização da saúde na Colômbia, no Peru e na Bolívia. A liderança do Brasil na região foi crítica para esses desenvolvimentos, uma vez que tinha sido instrumental na promoçáo da presença internacional da Unasul, assim como novas motivaçóes por redistribuição e direitos podem ser visualizadas nas iniciativas de Argentina e Equador em discutir o impacto de propriedade intelectual no acesso aos medicamentos ou o monopólio de empresas farmacêuticas no estabelecimento de preços e genéricos (Riggirozzi, 2015).

Isags teve suas atividades suspensas em 2019. A Escola Politécnica de Saúde Joaquim Venâncio (EPSJV), unidade técnico-científica da Fundação Oswaldo Cruz (Fiocruz), emitiu uma nota de apoio ao instituto, defendendo sua existência e atuação na área da diplomacia da saúde, defendendo que "o Isags realiza um inestimável trabalho voltado para a construção de políticas estruturantes e o fortalecimento do setor saúde na regiáo, por meio da gestáo do conhecimento e formaçáo de quadros nesse campo". ${ }^{14}$

O último relatório do Isags traz o Plano Operativo Anual 2019, incluindo as áreas: i) geração, produção e difusão do conhecimento; ii) apoio à formação de pessoal estratégico; iii) articulaçáo intersetorial; iv) contribuiçáo à democratizaçáo do acesso ao conhecimento e à informação; e v) fortalecimento da diplomacia da saúde. O relatório ainda relata que o Isags elaborou a base de dados Sur+, com informaçôes, séries estatísticas, mapas, gráficos e notícias relacionadas às assimetrias regionais e seus impactos na saúde. ${ }^{15}$ Desde 2018, o instituto vinha trabalhando para o lançamento de um novo site - atualmente, o portal e a base de dados não estão mais disponíveis. ${ }^{16}$

No caso do Prosul, considerado o substituto da Unasul, cabe reiterar que tal iniciativa náo abarca a totalidade dos países da regiáo e sua capacidade em dar respostas tem sido limitada, justamente pela falta de forte institucionalidade e corpo técnico para tratar os temas identificados pelos presidentes como prioritários.

Mesmo que o Prosul tenha proposto incorporar o acervo da integração regional e indicado que a saúde seria um dos temas prioritários, não houve incorporaçáo ou relançamento do Isags e nada

\footnotetext{
13. Mercado Comum do Sul.

14. Disponível em: <http://www.epsjv.fiocruz.br/nota-de-apoio-ao-instituto-sul-americano-de-governo-em-saude>.

15. Disponível em: <https://drive.google.com/drive/folders/1wb0e1nzCG6cRIsIK7GNdh8bMIxygSTpo>.

16. 0 domínio do site <isags-unasur.org> está sem registro.
} 
avançou na temática de 2019 até o surgimento da Covid-19. Segundo a Proposta Plano Setorial da Área Temática de Saúde ${ }^{17}$ do Prosul (Prosul, 2019), ${ }^{18}$ os componentes da agenda em saúde são os seguintes.

1) Envelhecimento ativo e saudável: "Desenvolver em colaboração políticas públicas que promovam o envelhecimento ativo e saudável, com base em um modelo sociossanitário e a partir de uma perspectiva de ciclo de vida” (Prosul, 2019, p. 4, tradução nossa).

2) Transformação digital: "Promover uma estratégia comum que utilize iniciativas digitais de transformação em saúde para reduzir as brechas de acesso, equidade e gestão de risco em populações específicas, colocando as pessoas no centro de nossa ação" (Prosul, 2019, p. 4, tradução nossa).

A partir disso, foram criados dois subgrupos (um para cada tema). O Peru é o país líder no subgrupo "envelhecimento ativo e saudável" (sendo Chile o alterno), enquanto Argentina, Colômbia, Equador e Paraguai são países participantes. No subgrupo "transformaçáo digital", o Chile é o país líder (sendo Peru e Colômbia os alternos), enquanto Argentina, Equador e Paraguai são países participantes. Apenas Brasil e Suriname não participam de nenhum dos subgrupos.

Ademais, o documento informa que essas duas áreas foram selecionadas por não repetir agendas prévias, não duplicar esforços com outros espaços de articulação regional e permitir que todos os países fossem beneficiados. Nesse sentido, ao não incorporar o Isags e o Conselho Sul-Americano de Saúde ou indicar que o acompanhamento epidemiológico da região seria uma linha temática, o Prosul não contava com um corpo técnico preparado para assessorar os governos. Assim, com a falta de institucionalidade, foi incapaz de coordenar açóes conjuntas - a realização de reuniốes, por exemplo, esteve a cargo do Chile, que exerce a presidência pro tempore do Prosul.

A primeira declaração do Prosul sobre a aparição do novo coronavírus foi publicada em 24 de janeiro de 2020. A nota informa que "as autoridades de saúde de nossos países se encontram em estado de alerta e comunicação permanente com as organizações de saúde competentes, tais como OMS e Opas, para evitar de forma coordenada a propagação da Covid-19 em nossa região" (Prosur, 2020a, tradução nossa). Ademais, a nota informa que o Grupo de Trabalho de Saúde do Prosul estava realizando consultas entre seus membros para adotar medidas de contençâo do vírus (op. cit.).

Na primeira declaração presidencial sobre a Covid-19, de 17 de março de 2020, os presidentes sugeriram a criação de um grupo ad hoc para o acompanhamento e a coordenação nos temas: aproximação de critérios para a tomada de decisão no manejo da emergência; trânsito e retorno de nacionais aos seus países de origem; intercâmbio periódico de informaçôes relativas à mobilidade de pessoas e à contenção dos impactos negativos sobre o comércio; intercâmbio de experiências para a criação de políticas públicas e medidas de mitigação; estabelecimento de medidas de coordenação visando às compras conjuntas de insumos médicos no marco da Opas; e coordenação de medidas de assistência econômica com organismos financeiros regionais - Banco Interamericano de Desenvolvimento (BID) e Banco de Desenvolvimento da América Latina (Corporación Andina de Fomento - CAF). Assinaram a declaração os chefes de Estado e altos representantes de Brasil, Chile, Colômbia, Equador, Guiana, Paraguai, Peru, Bolívia e Uruguai (Prosur, 2020b). Essa reuniáo foi marcada pela ausência

17. 0 documento data de dezembro de 2019, mas apenas foi disponibilizado para consultas no segundo semestre de 2020. Disponível em: $<$ https://web.archive.org/web/*/https://foroprosur.org/>.

18. Disponível em: <https://foroprosur.org/area-tematica/salud/>. 
do presidente brasileiro e pelo questionamento, feito pelo presidente argentino, sobre a ausência da Venezuela na reunião, uma vez que a coordenação entre todos os países da regiáo é necessária durante a crise (Figueiredo e Oliveira, 2020).

O que se observa a partir de então é que as posiçôes externadas pelo Prosul para a Covid-19 são do tipo declaratórias, sem necessariamente levar a efeitos concretos nas medidas públicas dos países - eles apenas trocam informaçóes sobre as experiências individuais e apontam para as medidas que o Prosul poderia adotar, por exemplo:

- buscar fontes conjuntas de financiamento para a compra coletiva de insumos médicos (Prosur, 2020c);

- contar com a quantidade apropriada de testes do tipo PCR, ${ }^{19}$ a fim de obter um mapeamento adequado da situação epidemiológica;

- coordenar respostas conjuntas e de cooperação nas zonas fronteiriças (Prosur, 2020d);

- adotar uma estratégia de reabertura progressiva de indústrias e setores produtivos;

- coordenar com organismos financeiros a expansão de linhas de crédito;

- averiguar a necessidade de atuação conjunta para a obtenção de vacinas e medicamentos para o tratamento do vírus (Prosur, 2020e);

- fazer a coordenação bilateral de trânsito fronteiriço;

- implementar "quarentenas inteligentes";

- coordenar esforços junto com instituiçôes financeiras multilaterais (BID, CAF e Fundo Monetário Internacional - FMI);

- fomentar a coordenação e a cooperação entre instituiçóes científicas e acadêmicas dos países do Prosul no desenvolvimento do conhecimento científico sobre a Covid-19;

- realizar esforços conjuntos para o breve desenvolvimento e o acesso a vacinas futuras e medicamentos na região; e

- atuar de maneira conjunta como regiáo para fortalecer a governança internacional no combate de epidemias e pandemias (Prosur, 2020f).

O último ponto evidencia que o desafio do Prosul durante a pandemia não é apenas enfrentar a Covid-19, mas atuar de maneira conjunta como regiáo e ter suas açôes validadas. Por exemplo, na reuniáo de coordenadores nacionais, concordou-se em enviar as declaraçóes presidenciais para determinados organismos internacionais multilaterais a fim de divulgar decisóes adotadas (Prosur, 2020g).

O Prosul esbarra também na dificuldade de os chefes de Estado participarem das reunióes presidenciais (como a ausência de alguns deles nas reunióes de presidentes do Prosul) e, assim, de se promover uma governança regional sem que todos os doze países da América do Sul participem. Além disso, ao preferir um esquema de integraçáo mais flexível e a criaçáo de grupos ad hoc para tratar dos temas (como no caso do grupo para a definição de açóes para a cooperação no âmbito

19. Polymerase chain reaction (em português, reação em cadeia da polimerase). 
sanitário e epidemiológico) (Prosur, 2020g), o Prosul náo garante a continuidade e a estabilidade dos trabalhos desenvolvidos.

No primeiro semestre de 2020, os trabalhos do Prosul, na presidência pro tempore do Chile, concentraram-se em buscar a coordenaçáo conjunta diante da pandemia, enquanto o Sica, a União Africana e a União Europeia seguiram discutindo outros temas relativos às suas agendas de integração regional, inclusive a econômico-comercial.

\section{COMÉRCIO INTERNACIONAL E REGIONAL NO CONTEXTO DA PANDEMIA DE COVID-19}

Nesta seção, são apresentados os impactos da pandemia da Covid-19 no comércio internacional e regional, comparando-se o desempenho recente do comércio bilateral de países líderes em quatro diferentes regiôes do mundo e avaliando-se o comércio do Brasil com os países da América do Sul no período recente.

\subsection{Impacto da Covid-19 no comércio internacional e regional}

As previsóes acerca do impacto econômico da pandemia da Covid-19 indicam um colapso na economia mundial. De acordo com o Banco Mundial, o produto interno bruto (PIB) global sofrerá uma contração do 5,2\% em 2020, a pior recessão desde a Segunda Guerra Mundial (Banco Mundial, 2020, p. 5). A Organização Mundial do Comércio (OMC) prevê uma forte queda do comércio de bens - entre $13 \%$ e $32 \%$-, com um débil crescimento econômico. ${ }^{20}$ Se bem a comercialização de serviços, particularmente os que dependem da proximidade física entre o prestador e o cliente foram severamente impactados, as limitaçóes no comércio de serviços afetam a produçáo de manufaturas. As restriçóes nas fronteiras e o colapso no transporte aéreo geraram um aumento nos custos de transporte internacional, ao passo que atrasos e irrupçóes na cadeia de fornecimento afetaram fortemente o setor industrial. ${ }^{21}$

O relatório de junho da Conferência das Naçôes Unidas para o Comércio e o Desenvolvimento (United Nations Conference on Trade and Development - Unctad) sinaliza que o comércio mundial contraiu-se no primeiro trimestre de 2020 e que essa tendência tende a se agudizar no segundo trimestre, com exceção da regiâo leste de Ásia e Pacífico. Em escala global, estima-se uma queda de $27 \%$ para o segundo trimestre de 2020 no valor do comércio internacional (Unctad, 2020). Em relação à América Latina, houve uma diminuição de $7 \%$ nas importaçôes e de $6 \%$ nas exportaçôes no primeiro trimestre de 2020. Para o segundo trimestre, a previsão é de queda de $30 \%$ nas importaçôes e de $20 \%$ nas exportaçóes. A queda das importaçóes maior que a das exportaçóes se deve ao fato de que vários países da regiáo têm suas exportaçôes concentradas no setor primário, e o comércio agroalimentar tem se mantido estável. ${ }^{22}$

De acordo com a Comissão Econômica para a América Latina e o Caribe (Cepal), o quinquênio 2014-2019 foi o período de menor crescimento econômico para a região dos últimos cinquenta anos

\footnotetext{
20. Disponível em: <https://www.wto.org/spanish/news_s/pres20_s/pr858_s.htm>.

21. Disponível em: <https://www.wto.org/english/tratop_e/covid19_e/trade_costs_report_e.pdf>.

22. Neste ponto, deve ser levada em conta a evolução dos preços internacionais desses produtos, assim como as medidas de restrição ao comércio que está tendo lugar de forma unilateral por parte de alguns países, visando garantir sua segurança alimentar.
} 
(Cepal, 2020, p. 8). O relatório de maio de 2020 prevê uma queda de 5,2\% da atividade econômica na América do Sul no ano e, em relação ao comércio, uma redução de 6\% do volume e de 17,6\% do valor comercializado. De acordo com Cepal (2020), a região se veria impactada pela diminuiçáo da atividade econômica na China, um dos principais sócios comerciais dos países da América do Sul (op. cit., p. 14). Contudo, a China, o Leste Asiático e a regiáo do Pacífico já apresentam sinais de recuperação e, ao analisar o comércio dos países sul-americanos com Ásia-Pacífico, observa-se o movimento contrário, com um forte aumento das exportaçôes dos países latino-americanos para essa região.

A Organização para a Cooperação e o Desenvolvimento Econômico (OCDE) chama a atenção sobre como a pandemia teria acelerado a mudança no padrão de interação entre os países em decorrência do fechamento de fronteiras e restriçóes comerciais. Estaria ocorrendo uma transição da "grande integração", uma referência aos avanços do multilateralismo na governança global nos anos 2000 , para a "grande fragmentação" ${ }^{33}$ e uma crise na governança global. Regionalmente, a crise na governança é reflexo da crescente fragmentação política e da desintegração econômica, fenômenos que se retroalimentam agudizando seus efeitos, formando uma espiral negativa.

O comércio intrarregional na América do Sul é historicamente baixo comparado a outras regióes. Sua principal economia, o Brasil, diminuiu suas exportaçóes totais para a América do Sul em 20,5\% entre 2018 e 2019. Quando se compara o primeiro semestre de 2020 com o mesmo período do ano anterior, a queda das exportaçóes brasileiras para a América do Sul é de 28,3\%, e suas importaçôes oriundas na região caíram $24,9 \%$ no período. ${ }^{24}$

O comércio intrarregional diminuiu em várias partes do globo. Segundo o BID, no primeiro trimestre de 2020, as exportaçóes intrarregionais diminuíram 3,8\% na Uniáo Europeia, 3\% na América do Norte e na 7,9\% América Latina (BID, 2020). Este artigo trabalha com a hipótese de que os efeitos da pandemia têm maior impacto no comércio intrarregional da América do Sul que no comércio da regiáo com o resto do mundo - e de que a recuperaçáo pós-pandemia nessa regiáo será mais lenta que a média global, devido à falta de coordenação econômica e de medidas para incentivar o comércio entre os países sul-americanos.

Busca-se comparar a evolução recente de quatro duplas de países líderes no comércio intrarregional de diferentes continentes como forma de suprir a ausência de dados atualizados para o período de maior impacto da pandemia. Em seguida, analisa-se a corrente de comércio do Brasil com os países da América do Sul, por se tratar da principal economia da regiáo e pela recente omissáo brasileira em relação a temas de governança regional. Apresentam-se também os fatores estruturais que mantêm o comércio intrarregional em um nível baixo na América do Sul e novos fatores que têm causado a diminuição da participação sul-americana no comércio exterior do Brasil.

\subsection{Comparação das relações comerciais bilaterais entre líderes regionais (Europa, Ásia, América do Norte e América do Sul)}

Devido à ausência de dados regionais atualizados para avaliar o impacto dos efeitos da pandemia no comércio intrarregional dos diferentes continentes, optou-se por analisar a dinâmica comercial recente

23. Disponível em: <http://www.oecd.org/perspectivas-economicas/junio-2020/>.

24. Disponível em: <http://www.oecd.org/perspectivas-economicas/junio-2020/>. 
de quatro duplas de países que são líderes em comércio em diferentes regiōes do mundo. Trata-se de economias integradas, afetadas pela pandemia da Covid-19 e que apresentam dados confiáveis atualizados até o fim de maio de 2020.

Selecionaram-se França e Alemanha, principais economias da União Europeia e o maior comércio bilateral da Europa; Estados Unidos e México, o principal comércio bilateral da América do Norte (North American Free Trade Agreement - Nafta), incluindo a economia latino-americana mais integrada a um país desenvolvido; China e Japão, as duas maiores economias asiáticas e do hemisfério oriental; e Brasil e Argentina, por serem as maiores economias da América do Sul e por apresentarem o maior nível de integração produtiva dessa regiáo desde o estabelecimento do Mercosul, em 1991.

Como o volume de comércio bilateral é muito distinto entre as duplas de países selecionadas, optou-se por se estabelecer como número-índice julho de 2018 e, de tal forma, comparar a dinâmica comercial entre os líderes e seu principal parceiro comercial regional de quatro diferentes continentes (América do Sul, América do Norte, Europa e Ásia) no período que antecede a pandemia e durante seus primeiros meses. Observa-se que, na América do Sul, a queda do comércio bilateral entre os parceiros líderes precede a pandemia, é mais acentuada e tende a se manter em um nível abaixo do período pré-pandemia. ${ }^{25} \mathrm{Na}$ Ásia, ${ }^{26} \mathrm{em}$ contrapartida, a recuperaçáo foi bastante rápida em março e abril, ainda que tenha tido uma nova queda em maio. Na América do Norte, ${ }^{27}$ o declínio foi tardio e mais acentuado que na Europa. ${ }^{28}$

No gráfico 1, apresenta-se a corrente de comércio de mercadorias entre os quatro pares de países (Estados Unidos e México; França e Alemanha; China e Japáo; e Argentina e Brasil) entre julho de 2018 e maio de 2020, tomando como base os valores de corrente de comércio relativos a julho de 2018. Os dados foram extraídos da base de dados estatísticos sobre comércio das ONU (United Nations International Trade Statistics Database - Comtrade) e da base de dados de comércio do Ministério da Economia do Brasil (Comex Stat).

No gráfico, pode-se observar que as correntes de comércio entre China e Japão, Estados Unidos e México e França e Alemanha se mantiveram relativamente estáveis no nível de fluxo comercial do mês-base (julho de 2018) durante o período analisado, até fevereiro-março de 2020. A corrente de

25. Em 7 de março, a Argentina registra a primeira morte por Covid-19; em 12 do mesmo mês, decreta a "emergência sanitária" e, posteriormente, o "isolamento preventivo e obrigatório", vigente até 20 de agosto, com exceção de províncias nas quais não havia casos de transmissão comunitária e nas quais passou a reger o "distanciamento preventivo". No Brasil, foi decretado o estado de emergência para conter o novo coronavírus no início de fevereiro e, em 25 do mesmo mês, foi confirmado o primeiro caso. A partir de março, alguns estados começaram a decretar medidas de distanciamento social. A quarentena não foi decretada nacionalmente - cada estado e município determinou as medidas de distanciamento social de acordo com sua avaliação da situação, o que aconteceu de forma díspar. Em abril, decreta-se o estado de calamidade pública ou a situação de emergência em alguns estados.

26. No Japão, o primeiro caso de Covid-19 foi registrado no início de janeiro. A partir de fevereiro, começaram as restrições de circulação, que foram se estendendo em março. Em abril, é decretado o estado nacional de emergência, que dura até o início de maio, mês em que se começa a flexibilização de medidas em algumas prefeituras. Na China, a primeira morte por Covid-19 é registrada em janeiro, e a partir de então se tomam medidas restritivas de prevenção, que se mantiveram até o final de março e que são retomadas toda vez que reaparece um surto. Na Ásia, priorizaram-se as medidas preventivas e as medidas restritivas nos locais onde existia maior risco de contágio.

27. Os Estados Unidos são o país com mais casos e mortes pela Covid-19. 0 primeiro caso foi registrado em 21 de janeiro e a primeira morte, no final de fevereiro. Desde o início da pandemia, houve restrições de entrada de estrangeiros, e, a partir da primeira morte, começam as medidas de isolamento social por estado, chegando em alguns casos a uma quarentena estrita. Em março, o presidente Trump declara emergência nacional.

28. Os primeiros casos de Covid-19 na Europa foram registrados na França e na Alemanha no final de janeiro. A Alemanha focou as medidas de prevenção e teve seu pico em abril, enquanto a França fez quarentena nacional por quinze dias em março, quando registrou seu maior número de casos. 
comércio do Brasil com a Argentina, por sua vez, apresenta uma tendência decrescente ao longo do período, que se acentuou a partir do segundo semestre de 2019. Em janeiro de 2020, o fluxo comercial entre esses dois países já havia perdido $40 \%$ do valor em relação a julho de 2018 . Após uma leve recuperação em fevereiro e março de 2020, o comércio bilateral Argentina-Brasil despencou em abril e maio de 2020, chegando a um valor mensal da corrente de comércio $60 \%$ menor que em julho de 2018. Verifica-se que a queda na corrente de comércio entre o Brasil e a Argentina foi maior que a das outras duplas de países analisados - esse movimento, intensificado nos últimos meses, já ocorria no período pré-pandemia.

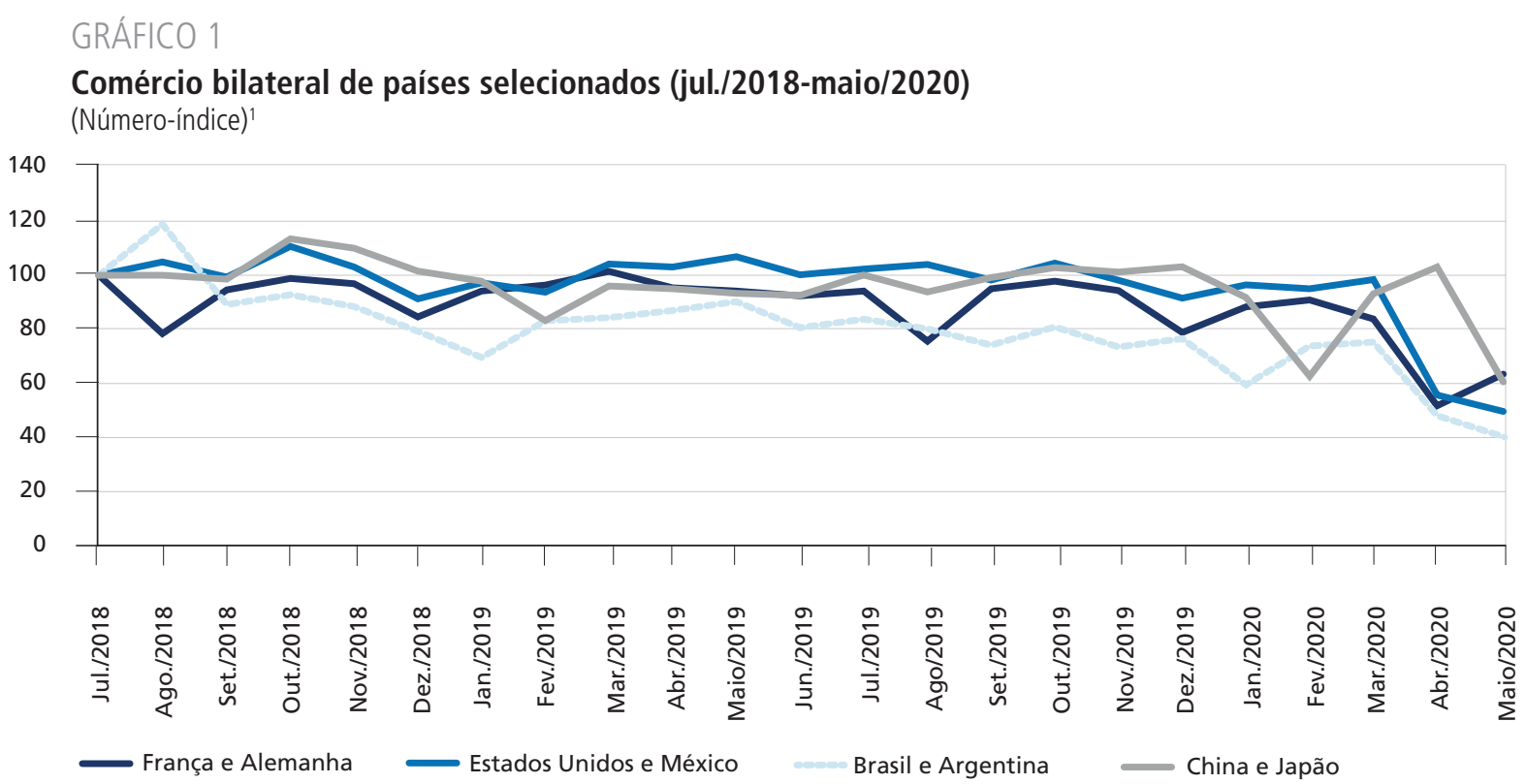

Fonte: Comtrade e Comex Stat.

Elaboração dos autores.

Nota: ${ }^{1}$ Julho de $2018=100$

\subsection{O comércio intrarregional do Brasil com os países da América do Sul}

A pandemia acentuou a tendência à desintegração comercial entre os países da América do Sul, o que já vinha se delineando nos últimos anos. O comércio do Brasil com a região vem decrescendo desde 2012. Ainda que tenha havido uma leve recuperação entre 2017 e 2018, em 2019 a participação da América do Sul na corrente de comércio do Brasil atingiu apenas 12\%, valor mais baixo desde o estabelecimento do Mercosul, em 1991. O superavit comercial anual do Brasil com os países de América do Sul diminuiu nos últimos anos. Entre 2005 e 2018, havia estado em torno de US\$ 10 bilhóes anuais, com alguns anos excepcionais. Em 2018, o superavit do Brasil com os países sul-americanos foi de US\$ 12,97 bilhóes, mas caiu 44\% em 2019, atingindo de US\$ 7,29 bilhóes (Samurio, Barros e Severo, 2019, p. 39).

As tabelas 1 e 2 apresentam as correntes de comércio do Brasil com os países da América do Sul no primeiro e segundo trimestres de 2018, 2019 e 2020, assim como as variaçóes percentuais entre os trimestres. A divisão em trimestres visa permitir a análise dos efeitos da pandemia da Covid-19 (segundo trimestre de 2020) de forma separada da queda previamente em curso (até o primeiro trimestre de 2020). 
A tabela 1 permite a comparação dos primeiros trimestres de 2018, 2019 e 2020. Observa-se que a queda da corrente de comércio entre o Brasil e a América do Sul entre 2018 e 2019 foi de 17\%; de 2019 para 2020, de 11,37\%. A queda no fluxo comercial com Argentina, Bolívia, Chile, Equador, Guiana, Paraguai e Venezuela foi mais acentuada entre 2018 e 2019 que em 2020. Os países que registraram maiores quedas no primeiro trimestre de 2020 em relaçáo ao mesmo período do ano anterior foram Colômbia (10,63\%), Peru (20,84\%) e Uruguai $(21,34 \%)$.

TABELA 1

Corrente de comércio do Brasil com os países da América do Sul (1ำ trim./2018, 2019 e 2020)

\begin{tabular}{|c|c|c|c|c|c|}
\hline & $\begin{array}{c}2018 \\
\text { (US\$ milhões) }\end{array}$ & $\begin{array}{c}2019 \\
\text { (US\$ milhões) }\end{array}$ & $\begin{array}{c}\text { Variação entre } 2018 \text { e } 2019 \\
(\%)\end{array}$ & $\begin{array}{c}2020 \\
\text { (US\$ milhões) }\end{array}$ & $\begin{array}{c}\text { Variação entre } 2019 \text { e } 2020 \\
(\%)\end{array}$ \\
\hline América do Sul & $14.223,4$ & $11.805,8$ & $-17,00$ & $10.463,5$ & $-11,37$ \\
\hline Bolívia & 678,2 & 728,2 & 7,36 & 686,6 & $-5,71$ \\
\hline Chile & $2.291,0$ & $1.954,5$ & $-14,69$ & $1.714,3$ & $-12,29$ \\
\hline Equador & 242,8 & 224,3 & $-7,62$ & 211,8 & $-5,56$ \\
\hline Guiana & 10,2 & 9,4 & $-8,43$ & 9,7 & 3,47 \\
\hline Paraguai & 949,7 & 826,2 & $-13,00$ & 848,0 & 2,63 \\
\hline Peru & 905,7 & 873,5 & $-3,56$ & 691,5 & $-20,84$ \\
\hline
\end{tabular}

Fonte: Comexstat.

Elaboração dos autores.

TABELA 2

Corrente de comércio do Brasil com os países da América do Sul (2ำ trim./2018, 2019 e 2020)

\begin{tabular}{|c|c|c|c|c|c|}
\hline & $\begin{array}{c}2018 \\
\text { (US\$ milhões) }\end{array}$ & $\begin{array}{c}2019 \\
\text { (US\$ milhões) }\end{array}$ & $\begin{array}{c}\text { Variação entre } 2018 \text { e } 2019 \\
(\%)\end{array}$ & $\begin{array}{c}2020 \\
\text { (US\$ milhões) }\end{array}$ & $\begin{array}{c}\text { Variação entre } 2019 \text { e } 2020 \\
(\%)\end{array}$ \\
\hline América do Sul & $14.608,9$ & $12.431,0$ & $-14,91$ & $7.268,7$ & $-41,53$ \\
\hline Bolívia & 746,0 & 589,4 & $-21,00$ & 365,1 & $-38,06$ \\
\hline Chile & $2.364,2$ & $2.185,9$ & $-7,54$ & $1.251,3$ & $-42,75$ \\
\hline Equador & 225,4 & 233,1 & 3,38 & 126,0 & $-45,95$ \\
\hline Guiana & 10,0 & 11,9 & 18,90 & 10,0 & $-15,36$ \\
\hline Paraguai & 923,6 & 882,0 & $-4,51$ & 623,5 & $-29,31$ \\
\hline Peru & 999,4 & 889,7 & $-10,97$ & 502,2 & $-43,55$ \\
\hline Suriname & 7,3 & 8,7 & 19,14 & 7,9 & $-9,29$ \\
\hline
\end{tabular}

Fonte: Comexstat.

Elaboração dos autores.

A tabela 2 permite observar os efeitos da pandemia na corrente de comércio do Brasil com os países vizinhos. A queda das trocas comerciais do Brasil com a América do Sul, no segundo trimestre de 2020, foi de 41,53\% em relação ao mesmo período do ano anterior. Com exceção da Venezuela, 
houve uma queda generalizada no segundo trimestre de 2020 contra igual período de 2019. Entre os segundos trimestres de 2018 e de 2019, o comércio do Brasil com Colômbia, Equador, Guiana e Uruguai havia crescido. No segundo trimestre de 2020, a corrente de comércio brasileira foi mais afetada com o Chile, a Colômbia, o Equador, a Guiana, o Peru e o Uruguai, em comparação com o mesmo período de 2019.

Quando se compara o segundo trimestre de 2020 com o mesmo período de 2018, somando-se os efeitos da crise econômica e da governança regional de 2019 com os da pandemia de 2020, verifica-se que as maiores quedas da corrente de comércio do Brasil com os vizinhos foram com a Argentina (59\%) e a Bolívia (51\%).

Ao mesmo tempo que a América do Sul vem perdendo importância para o comércio exterior do Brasil, a participação do Brasil no comércio exterior dos países da região também diminui. Em todos os casos, a queda da corrente de comércio com o Brasil tem sido mais acentuada que a diminuição das relações comerciais com o resto do mundo. No caso da Argentina, suas exportaçóes totais diminuíram $11 \%$ e suas importaçóes totais, 23,3\%. Já em relação ao Brasil, as quedas foram significativamente maiores, de $31,7 \%$ e $30,6 \%$, respectivamente, no mesmo período. ${ }^{29}$

O comércio exterior do Chile com o mundo registrou uma queda de 8,2\% no primeiro trimestre 2020 em comparaçáo com o mesmo período do ano anterior, sendo $4 \%$ nas exportaçóes e $13 \%$ nas importaçôes. As importaçóes de produtos brasileiros pelo Chile caíram 19\% primeiro trimestre de 2020, significativamente mais que a média mundial. ${ }^{30}$

No caso da Colômbia, as exportaçóes totais caíram 25,3\% no primeiro semestre de 2020, em comparaçáo com o primeiro semestre de 2019, e as importaçóes totais, entre janeiro e maio de 2020, diminuíram 18,3\% com relação aos mesmos meses de 2019. Entre junho de 2019 e junho de 2020, as exportaçôes brasileiras à Colômbia diminuíram 28\% e as importaçôes, 14,7\%, de acordo com Departamento Administrativo Nacional de Estatística (Dane) da Colômbia.

Em relação ao Peru, as exportações totais do país ao mundo registraram uma queda de 19,6\% e as importaçóes, $15,6 \%$, na comparação entre janeiro e maio de 2020 com o ano anterior. O Peru foi uma exceção regional porque não houve queda da participação relativa do Brasil no total de suas importaçôes, embora, durante o mês de maio (último mês com dados disponíveis), a queda das importaçóes oriundas do Brasil tenha sido de 38\%, acima dos 35\% da diminuição das importaçôes totais do Peru em comparação ao mesmo mês (Inei, 2020, p. 1 e 12).

Com relação ao Uruguai, as exportações totais ao mundo caíram 17,7\% ${ }^{31}$ entre janeiro e maio de 2020 em comparação com o mesmo período do ano anterior. Na comparação do comércio desses meses entre 2020 e 2019, as exportaçôes ao Brasil caíram 30\%, atingindo o nível mais baixo desde 2007 (Machado, 2020). As importaçôes do Uruguai de produtos brasileiros, por sua vez, despencaram $42 \%$ no mesmo período entre 2019 e 2020.

Existem fatores estruturais que explicam o baixo nível de comércio intrarregional na América do Sul: a deficiência da infraestrutura; a insuficiência dos instrumentos de financiamento e de garantias

29. Disponível em: <https://www.indec.gob.ar/uploads/informesdeprensa/ica_08_204916CE1AEF.pdf>. Acesso em: 24 set. 2020.

30. Disponível em: <https://www.subrei.gob.cl/docs/default-source/estudios-y-documentos/reporte-trimestral/comercio-exterior-de-chile-1ertrimestre-2020.pdf?sfvrsn=ebb087fb_2>.

31. Disponível em: <https://www.uruguayxxi.gub.uy/uploads/informacion/f2a809110e96766794d5597c8af59d570f30c734.pdf>. 
às exportaçóes; e a forma como as cadeias globais de valor (CGVs) estão estruturadas e como a região se insere como fornecedora de bens de baixo valor agregado (Samurio, Barros e Severo, 2019, p. 41), concentrados no início das CGVs, distantes dos centros desde os quais elas são dirigidas - o que implica maiores custos de transporte e logísticos.

Em contrapartida, evidenciam-se fatores conjunturais que aprofundam a desintegração econômica e a fragmentação política na América do Sul, a exemplo da diminuição da diplomacia presidencial; da paralisação das atividades dos instrumentos de governança de infraestrutura; do abandono das políticas públicas de internacionalização das empresas brasileiras por meio do Banco Nacional de Desenvolvimento Econômico e Social (BNDES); do baixo aporte ao orçamento do Fundo para a Convergência Estrutural do Mercosul (Focem) $;^{32}$ e da saída unilateral do Brasil do Convênio de Pagamentos e Créditos Recíprocos (CCR) da Associação Latino-Americana de Integração (Aladi) em abril de 2019.

A paralisação das atividades dos instrumentos de governança de infraestrutura (Cosiplan e Iniciativa para a Integração da Infraestrutura Regional Sul-Americana - IIRSA), desde o esvaziamento da Unasul, resultou na desatualização do banco de dados com mais de quinhentos projetos de infraestrutura, que foram atualizados anualmente entre o início da década de 2000 e o fim de 2017, e na desmobilizaçáo de dezenas de grupos de trabalho que acompanhavam os dez eixos de integração sul-americanos e seus principais projetos, com a exceção do Corredor Rodoviário Bioceânico, rota Porto Murtinho-Mato Grosso do Sul e portos do norte do Chile, que segue regularmente suas atividades.

Em decorrência do abandono das políticas públicas de internacionalização de empresas brasileiras concentradas no BNDES, as obras de infraestrutura diminuíram drasticamente. Entre 2000 e 2016, os desembolsos pós-embarque do BNDES para o financiamento das exportaçóes oscilaram entre US\$ 1,5 bilhão e US\$2,7 bilhóes, vindo a diminuir vertiginosamente para US\$ 400 milhóes em 2019. Entretanto, a oscilação da participação da América do Sul no total de desembolsos foi mais acentuada. Entre 2000 e 2006, era próxima a 10\%, mas chegou a superar 50\% em 2007, 2010 e 2011; em 2013, manteve-se acima dos 40\%; em 2016, foi de aproximadamente $1 \%$. Os anos em que houve mais desembolsos e incentivos às exportaçôes por parte do Estado brasileiro coincidiram com o período de maior comércio intrarregional do país com seus vizinhos. A Argentina foi o principal destino desses desembolsos, seguida pela Venezuela. Esses foram também dois dos países com os quais o Brasil registrou seus maiores superavit comerciais entre 2007 e 2013.

Em abril de 2019, o Banco Central do Brasil (BCB) ${ }^{33}$ comunicou sua saída unilateral do CCR, sistema de compensação de pagamentos criado no marco da Aladi para reduzir o fluxo intrarregional de divisas e fomentar a integração financeira e monetária. A decisão dessa autarquia brasileira não

32. 0 Focem é um fundo destinado a financiar projetos que ajudem a diminuir as assimetrias entre as economias do bloco. 0 Brasil aportava US\$ 100 milhões anuais, desde a criação do Focem até 2016. Em 2018, não houve aportes e, em dezembro de 2019, o presidente do Brasil, Jair Bolsonaro, anunciou o aporte de US\$12 milhões ao fundo e agregou que espera regularizar a situação com o fundo em um futuro próximo. Disponível em: <https://www.poder360.com.br/governo/bolsonaro-diz-que-brasil-vai-aportar-r-12-milhoes-em-fundo-do-mercosul/>.

33. De acordo com a circular do BCB (Brasil, 2019), a saída do Brasil da Aladi se justificaria pela pouca utilização do instrumento, pela ausência de problemas de liquidez, pelo anacronismo de sua governança, pelo risco de default e pelo fracasso das tentativas brasileiras de reformá-lo. Ainda que o mecanismo possa efetivamente ter problemas, o mais indicado seria que o Brasil propusesse mudanças em seu funcionamento, ou a criação de outro mecanismo que pudesse cumprir o papel desempenhado pelo CCR, que historicamente se mostrou importante para facilitar o comércio intrarregional. A forma e o conteúdo da saída brasileira do CCR sintetizam o momento de omissão do país em relação à agenda regional. De um lado, na política externa brasileira, a tentativa de promover reformas foi tímida, sem o protagonismo presidencial ou a interação conhecida com os países vizinhos; de outro, internamente, foi praticamente inexistente o debate formal nas instâncias de governo, como a Câmara de Comércio Exterior (Camex), do Legislativo, da Academia ou da imprensa. 
passou por instâncias competentes do Poder Executivo, nem pelas comissóes de relaçóes exteriores e de defesa nacional ou de assuntos econômicos do Senado Federal ou da Câmara dos Deputados.

\section{CONCLUSÕES}

A pandemia da Covid-19 se apresentou como um desafio às organizaçôes regionais e à capacidade delas de apresentar soluçóes e coordenar açóes conjuntas. Apesar de críticas focalizadas (no caso, alguns países em relação à União Europeia e El Salvador em relação à Sica), nenhuma das regiốes analisadas optou por tratar do tema de maneira individual. No caso da América do Sul, o que se observou foi a ausência de governança regional eficiente, o que agravou a situação da pandemia e compromete a retomada econômica.

Tendo em vista a reuniáo do Prosul, marcada pela ausência do presidente brasileiro e de outros chefes de Estado sul-americanos, observa-se que, sem instituiçóes regionais específicas para lidar com a questão, como no caso do Isags, outras iniciativas de integração ou concertação regional acabam tratando o tema de forma "fragmentada", ou seja, informam ou tomam açóes apenas nos países que conformam aquelas iniciativas. Seria um bom começo fortalecer o Prosul como "espaço de articulação da integração regional, incorporando temas e agendas ainda não contemplados por mecanismos como a (...) IIRSA, o (...) CDS e o (...) Isags", conforme as contribuiçóes do Ipea para o Brasil pós-Covid-19 (Ipea, 2020, p. 55).

Uma vez que a integração regional é um processo político, a pandemia da Covid-19 questiona a opção dos países de promover iniciativas de integração superficiais, promovendo cada vez menos a interdependência entre seus membros, desarticulada das políticas exteriores. Também é válido destacar o baixo protagonismo do Brasil, tanto na conformação do Prosul e de sua área temática sobre saúde quanto no tratamento da crise da Covid-19, se distanciando da tradição da política externa em defesa do direito à saúde.

A desintegração econômica e a fragmentação política já vinham desestruturando a governança regional no período que antecedeu a pandemia da Covid-19. Durante o período da pandemia, ambos os fenômenos se amplificaram e há evidências de que eles se retroalimentam. A falta de coordenação política para as fronteiras fez com que o comércio intrarregional caísse ainda mais. Persistindo a baixa concertação regional, a retomada econômica da América do Sul tende a ser mais lenta que a de outras regióes. A história do século XX mostrou que os momentos de crise econômica profunda foram preâmbulos para grandes conflitos e imensas perdas. O melhor remédio em momentos como este é aumentar a dose de concertação política regional e interdependência econômica.

\section{REFERÊNCIAS}

AFRICA UNION. Communiqué of the joint ministerial meeting of ministers of finance and ministers of health. Africa Union, 3 June 2020a. Disponível em: <https:/au.int/en/pressreleases/20200603/communiquejoint-ministerial-meeting-ministers-finance-and-ministers-health $>$.

. Communique of the virtual forum of the African Union ministers responsible for arts, culture, and heritage on their responses to the Covid-19 pandemic. Africa Union, 27 May 2020b. Disponível em: $<$ https://au.int/en/pressreleases/20200527/communique-au-ministers-arts-culture-and-heritage-their-responsescovid-19>. Acesso em: 3 ago. 2020. 
1st meeting of the taskforce on Covid-19 impact on food security and nutrition in Africa convened. Africa Union, 12 May 2020c. Disponível em: <https://au.int/en/pressreleases/20200512/1st-meetingtaskforce-covid-19-impact-food-security-and-nutrition-africa>. Acesso em: 3 ago. 2020.

African Union inaugurates Covid-19 diagnostic laboratory at their AU Pan African Veterinary Vaccine Centre. Africa Union, 8 May 2020d. Disponível em: <https://au.int/en/pressreleases/20200508/ african-union-inaugurates-covid-19-diagnostic-laboratory-their-au-pan-african>. Acesso em: 3 ago. 2020.

African ministers of Transport discuss actions to mitigate the devastating impacts of Covid-19 and address urgent challenges in transport sector. Africa Union, 21 Apr. 2020e. Disponível em: <https://au.int/en/pressreleases/20200421/ african-ministers-transport-discuss-actions-mitigate-devastating-impacts>. Acesso em: 3 ago. 2020.

The European Union supports Africa's Covid-19 continental response. Africa Union, 26 June 2020f. Disponível em: <https://au.int/en/pressreleases/20200626/european-union-supports-africas-covid19-continental-response>. Acesso em: 3 ago. 2020.

Government of Japan supports Africa's joint continental strategy for Covid-19 response. Africa Union, 26 July 2020g. Disponível em: <https://africacdc.org/news-item/government-of-japan-supportsafricas-joint-continental-strategy-for-covid-19-response/>. Acesso em: 3 ago. 2020.

Africa CDC and Mastercard Foundation partner to deliver one million test kits, deploy 10,000 community health workers for Covid-19 response. Africa Union, 4 June 2020h. Disponível em: <https:// au.int/en/pressreleases/20200604/africa-cdc-and-mastercard-foundation-partner-deliver-one-million-testkits>. Acesso em: 3 ago. 2020.

BANCO MUNDIAL. La COVID-19 (coronavirus) hunde a la economía mundial en la peor recesión desde la Segunda Guerra Mundial. Banco Mundial, 8 jun. 2020. Disponível em: <https://www.bancomundial.org/es/ news/press-release/2020/06/08/covid-19-to-plunge-global-economy-into-worst-recession-since-world-war-ii>.

BARROS, P. S.; GONÇALVES, J. de S. B. Fragmentação da governança regional: o Grupo de Lima e a política externa brasileira. Mundo e Desenvolvimento, v. 2, n. 3, p. 6-39, 2019.

BID - BANCO INTERAMERICANO DE DESARROLLO. El comercio intrarregional de América Latina cae fuertemente. Conexión Intal, mayo 2020. Disponível em: <https://conexionintal.iadb.org/2020/05/14/ el-comercio-intrarregional-de-america-latina-cae-fuertemente/>.

BÖRZEL, T. A. Theorizing regionalism: cooperation, integration and governance. In: BÖRZEL, T. A.; RISSE, T. (Ed.). The Oxford handbook of comparative regionalism. Oxford: Oxford University Press, 2016. p. 41-64.

BRASIL. Circular Bacen no 3.934, de 3 de abril de 2019. Dispóe sobre a vedação do registro de novas emissóes de instrumentos para curso no âmbito do Convênio de Pagamentos e Créditos Recíprocos (CCR) e altera a Circular no 3.871, de 21 de dezembro de 2017. Diário Oficial da Uniáo, Brasília, 5 abr. 2019. Disponível em: <https://www.legisweb.com.br/legislacao/?id=376416>.

CEPAL - COMISIÓN ECONÓMICA PARA AMÉRICA LATINA Y EL CARIBE. Informe sobre el impacto económico en América Latina y el Caribe de la enfermedad por coronavirus (COVID-19). Santiago: Naciones Unidas; Cepal, 2020. Disponível em: <https://www.cepal.org/es/publicaciones/45602informe-impacto-economico-america-latina-caribe-la-enfermedad-coronavirus-covid >.

FIGUEIREDO, J.; OLIVEIRA, E. Bolsonaro não participa de encontro virtual com presidentes de países do Prosul sobre coronavírus. O Globo, 16 mar. 2020. Disponível em: <https://oglobo.globo.com/mundo/ bolsonaro-nao-participa-de-encontro-virtual-com-presidentes-de-paises-do-prosul-sobre-coronavirus-24308147>. Acesso em: 25 abr. 2020.

FUCCILLE, A. et al. O governo Dilma Rousseff e a América do Sul: a atuação brasileira na Unasul (2011-2014). Colombia Internacional, n. 92, p. 43-72, 2017. Disponível em: <http://dx.doi.org/10.7440/ colombiaint92.2017.02>. 
GARCIA, A. S.; ASSIS, C. C. de; RIBEIRO, R. A. Covid-19 no continente africano: impactos, respostas e desafios. Brasília: Ipea, 2020. (Nota Técnica, n. 21). Disponível em: <https://www.ipea.gov.br/portal/images/ stories/PDFs/nota_tecnica/200807_nt_dinte_n_21.pdf>.

INEI - INSTITUTO NACIONAL DE ESTADÍSTICA E INFORMÁTICA. Evolución de las exportaciones e importaciones. Lima: Inei, 2020. (Informe Técnico, n. 7). Disponível em: <https://www.inei.gob.pe/media/ MenuRecursivo/boletines/boletin_export_import_mayo2020.pdf>.

IPEA - INSTITUTO DE PESQUISA ECONÔMICA APLICADA. O Brasil pós-Covid-19: contribuiçóes do Instituto de Pesquisa Econômica Aplicada. Brasília: Ipea, 2020. Disponível em: <https://www.ipea.gov.br/ portal/images/stories/PDFs/relatorio_institucional/200724_ri_o\%20brasil_pos_covid_19.pdfs.

KEOHANE, R. O; MARTIN, L. L. The promise of institutionalist theory. International Security, v. 20, n. 1, p. 39-51, 1995.

MACHADO, D. Exportaciones hacia Brasil cayeron al menor nivel desde 2007. El Observador, 26 jun. 2020. Disponível em: <https://www.elobservador.com.uy/nota/exportaciones-hacia-brasil-cayeron-al-menornivel-desde-2007--2020626224746>.

NAREA, M.; BENZI, D. Crónica de una secretaría general acéfala: un insumo para la interpretación de la crisis de la Unasur. Visioni LatinoAmericane, n. 22, p. 48-67, 2020.

NOLTE, D. Lo bueno, lo malo, lo feo y lo necesario: pasado, presente y futuro del regionalismo latinoamericano. Revista Uruguaya de Ciencia Política, v. 28, n. 1, 2019.

PROSUR - FORO PARA EL PROGRESO Y DESARROLLO DE AMÉRICA DEL SUR. Propuesta Plan Sectorial del área temática de Salud. Prosur, 2019. Disponível em: <https://foroprosur.org/wp-content/ uploads/2020/09/SALUD-PLAN_SECTORIAL_15-01-2020.pdf>. Acesso em: 24 ago. 2020.

. Declaración de Prosur sobre la propagación de brotes del Coronavirus 2019-nCoV. Prosur, 24 ene. 2020a. Disponível em: <https://foroprosur.org/declaracion-de-prosur-sobre-la-propagacion-de-brotes-delcoronavirus-2019-ncov/>. Acesso em: 3 ago. 2020.

. Declaración presidencial de Prosur sobre acciones conjuntas para enfrentar la pandemia del coronavirus. Prosur, 17 mar. 2020b. Disponível em: <https://foroprosur.org/declaracion-presidencial-de-prosur-sobreacciones-conjuntas-para-enfrentar-la-pandemia-del-coronavirus/>. Acesso em: 3 ago. 2020.

. Segunda videoconferencia de presidentes de Prosur por Covid-19. Prosur, 13 abr. 2020c. Disponível em: <https://foroprosur.org/segunda-videoconferencia-de-presidentes-de-prosur-por-covid-19/>. Acesso em: 3 ago. 2020.

Tercera reunión de ministros de Salud de Prosur. Prosur, 4 mayo 2020d. Disponível em: <https:// foroprosur.org/tercera-reunion-de-ministros-de-salud-de-prosur/>. Acesso em: 3 ago. 2020.

Tercera reunión de presidentes de Prosur por Covid-19. Prosur, 19 mayo 2020e. Disponível em: $<$ https://foroprosur.org/tercera-reunion-de-presidentes-de-prosur-por-covid-19/>. Acesso em: 3 ago. 2020.

Segunda declaración presidencial de Prosur sobre acciones conjuntas para enfrentar la pandemia del coronavirus. Prosur, 26 mayo 2020f. Disponível em: <https:/foroprosur.org/segunda-declaracion-presidencialde-prosur-sobre-acciones-conjuntas-para-enfrentar-la-pandemia-del-coronavirus/>. Acesso em: 3 ago. 2020.

Nota de prensa sobre la II reunion de coordinadores nacionales de Prosur. Prosur, 3 jun. 2020g. Disponível em: <https://foroprosur.org/nota-de-prensa-sobre-la-ii-reunion-de-coordinadores-nacionales-deprosur/>. Acesso em: 3 ago. 2020.

RIGGIROZZI, P. Regionalism, activism, and rights: new opportunities for health diplomacy in South America. Review of International Studies, v. 41, n. 2, p. 407-428, 2015. 
Coronavirus y el desafío para la gobernanza regional en América Latina. Análisis Carolina, n. 12, p. 1-13, 2020.

RIGGIROZZI, P.; TUSSIE, D. The rise of post-hegemonic regionalism in Latin America. In: (Ed.). The rise of post-hegemonic regionalism: the case of Latin America. Dordrecht: Springer, 2012. p. 1-16.

SAMURIO, S. E.; BARROS, P. S.; SEVERO, L. W. O protagonismo do Brasil na integração da sul-americana: uma análise das relaçóes comerciais 2000-2018. Revista Oikos, v. 18, n. 1, p. 38-54, 2019.

SICA - SISTEMA DE LA INTEGRACIÓN CENTROAMERICANA. Declaración de los jefes de Estado y de gobierno de Belize, Costa Rica, Guatemala, Honduras, Nicaragua, Panamá y República Dominicana ante la pandemia de Covid-19. El Salvador: SG-Sica, 2020a. Disponível em: <https:/www.sica.int/documentos/ declaracion-de-los-jefes-de-estado-y-de-gobierno-de-belize-costa-rica-guatemala-honduras-nicaragua-panamay-republica-dominicana-ante-la-pandemia-de-covid-19_1_121406.html>. Acesso em: 3 ago. 2020.

. Observatorio Regional Sica-Covid-19, todo lo que necesitas saber del coronavirus en Centroamérica. Sica, 8 jul. 2020b. Disponível em: <https://www.sica.int/noticias/observatorio-regional-sica-covid-19-todolo-que-necesitas-saber-del-coronavirus-en-centroamerica_1_122785.html>. Acesso em: 3 ago. 2020.

SICA: Rusia dona 30 mil pruebas Covid-19 a la región centroamericana. Sica, 10 jul. 2020c. Disponível em: <https://www.sica.int/noticias/sica-rusia-dona-30-mil-pruebas-covid-19-a-la-regioncentroamericana_1_122847.html>. Acesso em: 3 ago. 2020.

Países miembros del SICA recibirán más de 180 mil pruebas para el Covid-19. Sica, 3 abr. 2020 d. Disponível em: <https://www.sica.int/noticias/paises-miembros-del-sica-recibiran-mas-de-180-mil-pruebaspara-el-covid-19_1_121595.html>. Acesso em: 3 ago. 2020.

. SG-Sica y República de China (Taiwán) anuncian fondo de US\$4 millones para enfrentar el coronavirus. Sica, 31 mar. 2020e. Disponível em: <https://www.sica.int/noticias/sg-sica-y-republica-de-china-taiwananuncian-fondo-de-us-4-millones-para-enfrentar-el-coronavirus_1_121560.html>. Acesso em: 3 ago. 2020.

UNCTAD - UNITED NATIONS CONFERENCE ON TRADE AND DEVELOPMENT. Global trade continues nosedive, Unctad forecasts 20\% drop in 2020. Unctad, 11 June 2020. Disponível em: <https:// unctad.org/en/pages/newsdetails.aspx?OriginalVersionID=2392>.

UNIÃO EUROPEIA. Roteiro para a recuperaçáo: rumo a uma Europa mais resiliente, mais sustentável e mais justa. Bruxelas: Uniáo Europeia, 2020a. Disponível em: <https://www.consilium.europa.eu/ media/43420/20200421-a-roadmap-for-recovery_pt.pdf>. Acesso em: 3 ago. 2020.

Orçamento de longo prazo da UE para 2021-2027. Conselho Europeu, 28 jul. 2020b. Disponível em: <https://www.consilium.europa.eu/pt/policies/the-eu-budget/long-term-eu-budget-2021-2027/>. Acesso em: 3 ago. 2020.

A resposta comum da UE ao surto de Covid-19. Uniáo Europeia, 2020c. Disponível em: <https:// europa.eu/european-union/coronavirus-response_pt>. Acesso em: 3 ago. 2020. 
